\title{
Ilustração de espécimes do gênero Paypayrola (Violaceae)
}

\author{
Lucas Carneiro dos Santos $^{1}$; Ivoneide de França Costa ${ }^{2}$; \\ 1. Bolsista PIBIC/CNPq, Graduando em Nome do Curso, Universidade Estadual de Feira de Santana, e-mail: \\ lucascarneirods@hotmail.combr \\ 2. Orientador, Departamento de nome, Universidade Estadual de Feira de Santana, e-mail: neidefc@uefs.br
}

PALAVRAS-CHAVE: Desenho, Ciência, Paypayrola.

\section{INTRODUÇÃO}

O desenho esta presente na história da humanidade desde os tempos remotos. As pinturas rupestres são evidências de que o homem primitivo, muito antes do advento da escrita, já utilizava uma forma de registro representando as atividades que faziam parte do seu cotidiano, as pessoas com as quais conviviam, os animais que caçavam e muitos outros fenômenos da natureza. Esses desenhos estão distribuídos por quase todo o planeta e serviam como uma forma de comunicação entre esses povos, o que nos dias atuais nos permitem conhecer um pouco do cotidiano dos mesmos, suas concepções e propósitos.

Ao longo do desenvolvimento da humanidade e o surgimento da oralidade o desenho também pode se desenvolver como uma linguagem própria, aperfeiçoando seu caráter descritivo e ao mesmo tempo interpretativo (CARNEIRO, 2011). Desde esse período, o desenho tem sido um dos mais eficazes meios de comunicação e expressão.

Através do Renascimento Cultural, na Europa do século XIV, a matemática e às ciências da natureza ganharam grande destaque, influenciando esteticamente artistas do período. Isso permitiu o desenvolvimento de novas técnicas de proporção e perspectiva, através das quais a pintura e a escultura renascentista pretendiam se aproximar ao máximo da realidade. Nesse período, surge a ciência moderna e junto com ela uma visão da arte do desenho como instrumento da ciência, a ilustração científica. A principal função desse poderoso instrumento está na capacidade de representação, visto que "o desenho é uma das formas de expressão humana que melhor permite a representação das coisas concretas e abstratas que compõem o mundo natural ou artificial em que vivemos" (GOMES, 1996, p. 13).

O cientista se utiliza do desenho para realizar experimentos, a fim de obter meios de investigação operativa (BELLUZZO, 1994), como também para confirmar os dados obtidos em experimentações. Ou seja, o desenho se apresenta ao cientista como elemento fundamental para o desenvolvimento e comprovação da ciência.

Nesse sentido, presente plano de trabalho teve por objetivo pesquisar e representar graficamente plantas através de técnicas de ilustração cientifica. Objeto escolhido para estudo foram plantas pertencentes à família Violacea. Embora não seja um grupo muito comum, as Violaceas apresentam distribuição cosmopolita, possuindo representantes em diversos ecossistemas. Segundo Souza \& Lorenzi (2012), o interesse econômico desse grupo de plantas concentra-se nas espécies ornamentais, com destaque para a Viola tricolor, também conhecida popularmente como amor perfeito; e espécies de violeta (Viola spp.). Já outras espécies são empregadas para fins medicinais, como é o exemplo da chamada ipecacuanha-branca (Pombalia spp.). Essa planta é utilizada no tratamento da tosse e é encontrada amplamente no campus da Universidade Estadual de Feira de Santana (UEFS).

Existem poucos trabalhos publicados sobre a família em questão e não existindo ainda nem um trabalho que trate da família Violaceae para o estado da Bahia. Segundo alguns autores a carência de ilustração, chave para identificação e a falta de dados mais 
específicos sobre a morfologia dessas espécies dificulta o trabalho na sua identificação, o que reforçou a escolhe pelo grupo.

Violacea também é um dos muitos grupos de plantas que atualmente estão sendo estudadas no projeto desenvolvido no âmbito da UEFS em conjunto com outras universidades públicas do estado da Bahia, intitulado Flora da Bahia, cujo objetivo é identificar e catalogar as plantas que ocorrem no estado da Bahia. Sendo assim, o trabalho veio a contribuir para o andamento desse projeto.

\title{
MATERIAL E MÉTODOS OU METODOLOGIA (ou equivalente)
}

Os materiais utilizados durante o desenvolvimento das atividades do plano de trabalho foram: lápis grafite, tinta aquarela, papel canson e máquina fotográfica, todos disponibilizados pelo projeto de pesquisa a que o presente plano se vincula. A identificação das espécies foi feita em conjunto com outros pesquisadores botânicos do herbário da UEFS que desenvolvem trabalhos sobre espécies de Violaceae na Bahia. As plantas foram representadas através da técnica de grafite

\section{RESULTADOS E/OU DISCUSSÃO (ou Análise e discussão dos resultados)}

Com o intuito de melhorar a compreensão e sua utilização na vida humana, as plantas tornaram-se fonte de investigação muito antes do surgimento da ciência. A partir da necessidade de conhecer e identificar as plantas, o desenho passou a ser utilizado na caracterização e descrição dos vegetais. Sociedades antigas, como os egípcios, utilizavam de gravuras para representar os vegetais usados em sua culinária e na medicina, por exemplo, como afirma Pereira:

\footnotetext{
Os desenhos botânicos são utilizados na descrição e identificação taxonômica de plantas. Eles são encontrados em estudos de anatomia vegetal, citologia, ecologia e morfologia. As ilustrações são uteis em publicações de divulgação cientifica, como jornais e revistas, livros e guias de campo, rótulos de fármacos e cosméticos (PEREIRA, 2008).
}

A ilustração científica é um tipo de representação que tem por objetivo traduzir e comunicar, através das imagens, observações e conhecimentos científicos; elucidando seus aspectos e dando-lhes maior visibilidade. Uma das principais características que a defini é a possibilidade de destacar, através do foco, detalhes que são de interesse do ilustrador.

O desenho também possibilita tornar visíveis imagens construídas a partir de fragmentos:

\begin{abstract}
Uma ilustração cientifica pode, assim, reconstruir o passado e projetar o futuro. Recupera imagens de espécies extintas e mostra uma nave espacial antes mesmo de ela ser construída- chagando ao seu destino. Em algumas circunstancias, apenas sob a forma de desenho, é possível, por exemplo, mostrar-se como era um dinossauro, ou descrever-se os passos de uma cirurgia que vai ser realizada ou, ainda, apresentar a paisagem de outra era geológica. (PEREIRA, 2007)
\end{abstract}

Deve-se ressaltar que uma ilustração científica não é necessariamente uma cópia do que se vê. Segundo Pereira (2007), mesmo que o desenho se constitua como uma representação fiel, ele não deixa de ser uma interpretação do modo tanto de ver quanto de registrar graficamente.

Existe uma grande variedade de meios e técnicas que podem ser utilizadas em uma ilustração científica biológica. A escolha depende, entre outras coisas, do tempo disponível e da finalidade da publicação. Dentre as técnicas mais utilizadas nas 
publicações científicas estão o grafite, tintas guache, nanquim, acrílica e computação gráfica (PEREIRA, 2007). Em todas elas, o olhar sobre o objeto é importante. Observar a diversidade de formas e cores que compõem a natureza requer tempo e sensibilidade.

Uma convenção bem firmada é o posicionamento do foco luminoso. Na ilustração cientifica a luz deve-se localizar, sempre, do lado esquerdo e acima em relação ao objeto que vai ser desenhado:

Na ilustração é usual que a fonte de luz primaria esteja num ângulo de 45 graus em relação ao plano que o objeto se apoia. Para auxiliar na percepção da tridimensionalidade da forma, deve-se localizar uma fonte de luz secundaria, ou luz refletida, à direita, logo à baixo do plano de apoio. (PEREIRA, 2007).

A luz incidente e as sobras projetadas à partir dela revela a tridimensionalidade dos objeto e é possível representa-los através de técnicas de sombreamento. Para isso é necessário à presença de, pelo menos, uma fonte luminosa. Segundo Pereira (2008), a iluminação e o sombreamento são elementos indissociáveis ao desenho de observação.

Embora não seja um grupo muito comum, as Violaceas apresentam distribuição cosmopolita, possuindo representantes em diversos ecossistemas. Grande parte das plantas pertencentes a essa família são ervas de regiões temperadas.

Todos os gêneros dessa família têm suas flores polinizadas por insetos. As flores são visitadas por diversas espécies de moscas, abelhas, vespas e borboletas e são tipicamente alógamas, ou seja, fazem preferencialmente a polinização cruzada. As pétalas frequentemente apresentam estruturas denominadas "Guias de néctar" que possui a função de atrair polinizadores para o interior da flor. O néctar, ou recompensa floral, é estocado em uma pétala modificada em forma de esporão (Judd et al, 2009).

Atualmente foram catalogadas 800 espécies pertencentes à família Violaceae em todo mundo, organizadas filogeneticamente em 21 gêneros. No Brasil ocorrem 14 desses gêneros com cerca de 74 espécies, a maioria pertencente ao gênero Pombalia e Rinorea. Na Bahia, as Violaceaes incluem 9 gêneros e 23 espécies de plantas que podem futuramente ser utilizadas com propriedades ornamentais tendo em vista a grande beleza de suas flores.

Dentre os gêneros do estado da Bahia temos o gênero Paypayrola, que são geralmente arvoretas de aproximadamente $1,5 \mathrm{~m}$ de altura. Apesar dos avanços nos conhecimentos da sistemática de Paypayrola pouco se conhece sobre propriedades medicinais e ecológicas de grupo que geralmente ocorre em matas fechadas principalmente no sul da Bahia.

Dentro do gênero Paypayrola, selecionamos como objeto de estudo três espécies que possuem ocorrência no estado da Bahia: P. blanchetiana, endêmica do Brasil, P. grandiflora e P. longifolia e, ambas nativas. Elas apresentam apenas descrição em latim que estão disponíveis na obra Flora brasiliensis, não havendo nenhum outro trabalho com descrição e ilustrações.

Realizamos a descrição das três espécies da forma como é exigido pelos veículos de publicação. Os caracteres foram denominados através de termos científicos botânicos.

\section{Ilustrações produzidas:}




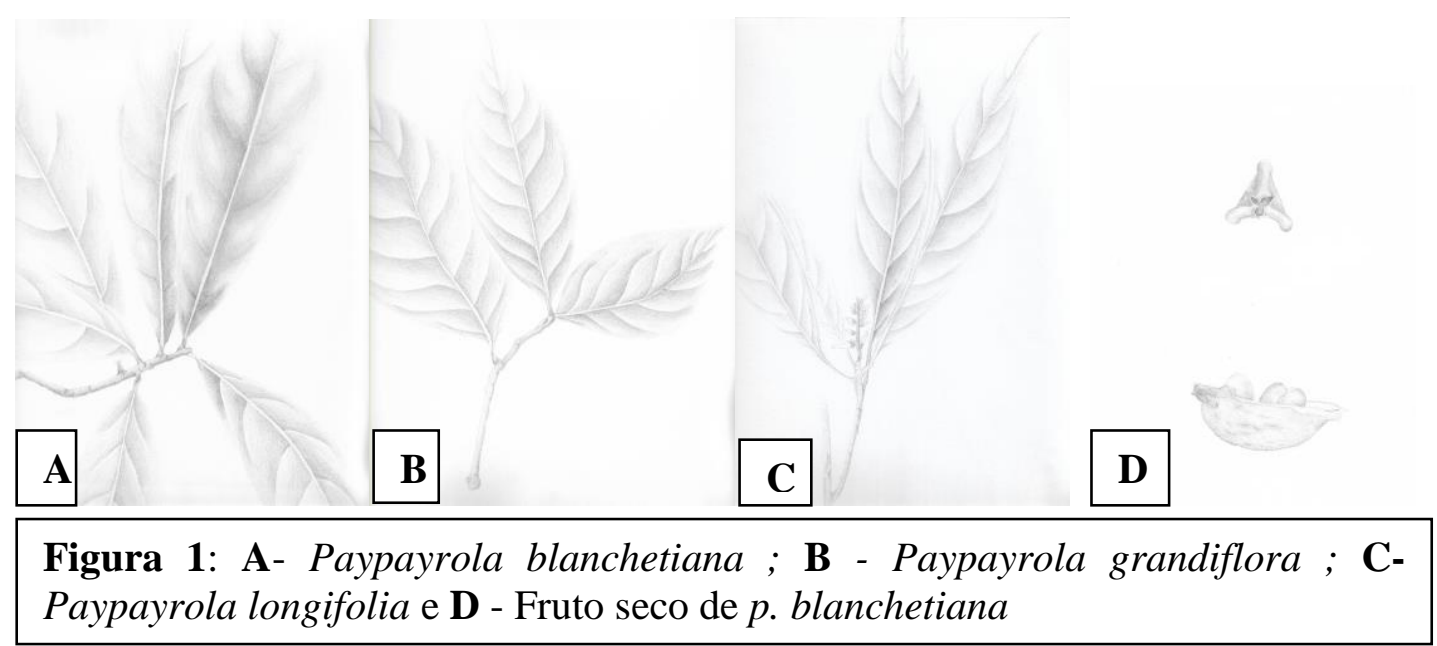

\section{CONSIDERAÇÕES FINAIS (ou Conclusão)}

As espécies pertencentes à família das Violaceas que possuem ocorrência no estado da Bahia são: Paypayrola grandiflora, Paypayrola blanchetiana e Paypayrola longifólia. Os aspectos biológicos do gênero Paypayrola e as características morfológicas das três espécies foram representados através de desenhos em grafite. Atualmente nove gêneros de Violaceae são conhecidos no estado da Bahia, comportando 23 espécies. Ressaltamos a importância de novos trabalhos destinados à produção de ilustrações da família, a fim de contribuir para estudo e comunicação da diversidade biológica que compõe a flora baiana.

\section{REFERÊNCIAS}

PEREIRA, R. M. A. Cadernos de Ilustração Científica 1: ABCDesenho. PROEX UFMG- Pró Reitoria de extensão, Belo Horizonte, 2007.

PEREIRA, Rosa Maria Alves, Cadernos de Ilustração Científica 2, Ilustração Botânica, PROEX UFMG- Pró Reitoria de extensão, Belo Horizonte, 2008.

Claudio Luiz Mangini Juliana Cavalaro. Ilustrador. IFPR - INSTITUTO FEDERAL DO PARANÁ. 2012

CARNEIRO, Diana. Ilustração Botânica: Princípios e Métodos. Curitiba, PR: Editora UFPR, 2011.

GOMES, Luis Vidal Negreiros. Desenhismo. 2 ed. Santa Maria: UFSM, 1996

SOUZA, Vinícius Castro. Botânica Sistemática: Guia Ilustrado para Identificação das Famílias de Fanerógamas Nativas e Exóticas no brasil. São Paulo: Instituto Plantarum, 2012 . 